\title{
Volatile sulphur compounds in wines related to yeast metabolism and nitrogen composition of grape musts
}

\author{
N. Moreira ${ }^{a}$, F. Mendes $^{a}$, O. Pereira ${ }^{b}$, P. Guedes de Pinho ${ }^{a}$, \\ T. Hogg , I. Vasconcelos \\ ${ }^{a}$ Escola Superior de Biotecnologia, Universidade Católica Portuguesa, Rua Dr. António Bernardino de Almeida, 4200-072 Porto, Portugal

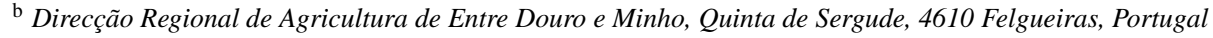

Keywords: Sulphur compounds; Amino acid composition; Fermentation; Wine

\begin{abstract}
The influence of nitrogen compounds in grape musts on the content of sulphur compounds of wines was studied. Different vinifications were performed with the addition of methionine $\left(20 \mathrm{mg} \mathrm{l}^{-1}\right)$ and/or cysteine $\left(40 \mathrm{mg} \mathrm{l}^{-1}\right)$ to grape musts before alcoholic fermentation. Six grape musts, with different nitrogen composition, from cultivars of the 'Vinhos Verdes' Region, in Portugal, were used. Addition of methionine to grape musts enhanced the content of wines in 3-(methylthio)-1-propanol, acetic acid-3-(methylthio)propyl ester, 3-(methylthio)propionic acid and some unidentified sulphur compounds. Increase of cysteine concentration in musts led to the production of wines with high levels of hydrogen sulphide and cis-2-methyltetrahydrothiophene-3-OL and also unidentified sulphur compounds; however, the content of 3-(methylthio)propionic acid in the wines decreased considerately with the addition of cysteine to grape musts. This work showed that cultivars from the Vinho Verde Region show different sulphur compound contents. Avesso wines, elaborated from grape musts with low amino acids level, presented the highest total sulphur compounds content. Wines from Azal branco and Alvarinho were characterised by high contents of 4-(methylthio)-1-butanol and 3-(methylthio)propionic acid, respectively. A high content of $\mathrm{N}$-(3-(methylthio) propyl)-acetamide and dimethylsulphone characterise the Loureiro wines. In contrast, Trajadura wines, produced from a must rich in amino acids, presented a low total sulphur compounds content; however, these wines were also characterised by high concentrations of 4-(methylthio)-1-butanol, acetic acid-3-(methylthio)propyl ester and hydrogen sulphide.
\end{abstract}

\section{Introduction}

In recent years, the composition in sulphur compounds of wines has become a subject of many studies concerning their identification and origin, as well as their character and impact on wine quality. Generally, sulphur compounds are classified as detrimental to wine quality; however, new developments in wine

\footnotetext{
* Corresponding author. Fax: +351-2-5090351.

E-mail address: ivasc@esb.ucp.pt (I. Vasconcelos).
}

research allowed the differentiation of a family of sulphur compounds responsible for a varietal aroma of wines [1]. Further investigation is required to better understand the origin of these compounds and their impact on sensory properties of wines.

Volatile sulphur compounds in wines are classified into two categories according to their bp: the highly volatile compounds ( bp $<90^{\circ} \mathrm{C}$ ) and the less volatile compounds (bp $>90^{\circ} \mathrm{C}$ ) [1-3]. The highly volatile compounds, particularly hydrogen sulphide, ethanethiol and methanethiol, are present in reduced 
wines and, at concentrations higher than their perception threshold, they are sensed by rotten eggs, garlic, onion and cabbage smells; however, they do not pose a serious problem to wine, as their boiling point is relatively low and, therefore, most of them are volatilised by simple racking and aeration. Other highly volatile sulphur compounds, such as carbonyl sulphide and dimethyl sulphide, are less significant in reduction defects. The latter has been considered by some authors to contribute to the bouquet of wines [4].

Among the less volatile sulphur compounds, 3-(methylthio)-1-propanol (methionol) is present in wines at concentrations up to $5 \mathrm{mgl}^{-1}$. When this compound occurs at concentrations above its threshold value $\left(1.2 \mathrm{mg} \mathrm{l}^{-1}\right)$, it contributes a cauliflower aroma [1,2]. Among the many other less volatile sulphur compounds identified in wine, with low detection limits, most of them are usually found at levels below their threshold value; these include 2-mercaptoethanol (poultry-like aroma), 2-methyltetrahydrothiophen-3one (metallic, natural gas odour), 2-methylthioethanol (French bean), ethyl-3-methylthiopropionate (metallic, sulphur aroma), acetic acid-3-(methylthio)propyl ester (cooked potatoes) and 4-methylthiobutanol (chive-garlic aroma) $[1,2,5]$.

The mechanism of production of many sulphur compounds is still not well-known. Beside enzymatic formation resulting from yeast metabolism, other nonenzymatic reactions may occur during vinification through the influence of temperature, light and chemical transformation. Moreover, sulphur-containing pesticides or other breakdown products can be used as precursors in biochemical reactions arising from grape juice enzymes or yeast metabolism [5].

The reduction of sulphate and sulphite by yeasts results in the production of hydrogen sulphide [6-9]. Hydrogen sulphide is an essential metabolic intermediate in the biosynthesis of cysteine and methionine necessary for protein synthesis and cellular metabolism. Hydrogen sulphide may also be produced from cysteine through its degradation directly to sulphide by the cysteine desulphydrase of yeast [5-11]. Dimethyl sulphide is synthesised by yeast from cysteine, cystine and glutathione [1] or it can be produced from dimethyl sulphoxide by yeast reductase $[3,11]$.

Sulphur amino acids and precursors mediate the production of organic sulphur compounds in wines, followed by the Ehrlich reaction. The production of 3-(methylthio)-1-propanol, for instance, is wellknown; this compound is produced by yeast from methionine, via deamination, followed by decarboxylation (Ehrlich reaction). The aldehyde thus formed (methional) is reduced by an enzymatic reaction into an alcohol. The biosynthesis of 4-(methylthio)-1butanol from homomethionine and 2-mercaptoethanol from cysteine was also proposed [1,5,12].

The aim of this study is to determine the influence of nitrogen compounds in grape musts and yeast metabolism on the production of sulphur compounds in wines. Six grape musts, with different nitrogen composition, were used. Different vinifications were also performed with the addition of methionine and/or cysteine to grape must before alcoholic fermentation.

\section{Materials and methods}

\subsection{Grape musts and fermentations}

Experiments were carried out on white musts obtained from grapes of the Vitis vinifera varieties from the Vinho Verde Region in Portugal (Alvarinho, Loureiro, Trajadura, Pedernã, Azal branco and Avesso), in the 1999 vintage. Duplicate vinifications were performed with the addition of methionine $\left(20 \mathrm{mg} \mathrm{l}^{-1}\right)$ and/or cysteine $\left(40 \mathrm{mg} \mathrm{l}^{-1}\right)$ to grape must before alcoholic fermentation. All fermentations were conducted in 101 tanks, at $18^{\circ} \mathrm{C}$, with inoculation of a rehydrated strain of Saccharomyces cerevisiae ph.v. cerevisiae (commercial name Fermol Bouquet, from Pascal Biotech, controlled by the General Microbiology Laboratory of the Faculty of Science of the University of Reims-Champagne, France).

\subsection{Analytical determinations}

The amino acids content of musts was quantified by liquid chromatography using a Beckman (System Gold) chromatograph, according to the method described by Pripis-Nicolau et al. [13].

Higher molecular weight sulphur compounds, dimethyl sulphide and hydrogen sulphide were determined using a Hewlett-Packard 5890 gas chromatograph, equipped with a flame photometric detector and the H.P. Chemstation software. An amount of $50 \mathrm{ml}$ of wine, with ethyl (methylthio)acetate $\left(50 \mu \mathrm{gl}^{-1}\right)$ 
as internal standard, was extracted twice with $5 \mathrm{ml}$ portions of dichloromethane for $5 \mathrm{~min}$. The organic phases were concentrated to $1 / 10$ under a nitrogen atmosphere. The extract $(2 \mu \mathrm{l})$ was injected (splitless,
0.3 min) into a CP-WAX 58 (FFAP)-CB column (Chrompack) of $50 \mathrm{~m} \times 0.32 \mathrm{~mm}$ and $0.2 \mu \mathrm{m}$ phase thickness. The temperature programme was $40^{\circ} \mathrm{C}$ $(10 \mathrm{~min})-220^{\circ} \mathrm{C}(40 \mathrm{~min})$ at $2{ }^{\circ} \mathrm{C} \mathrm{min}{ }^{-1}$. Injector and
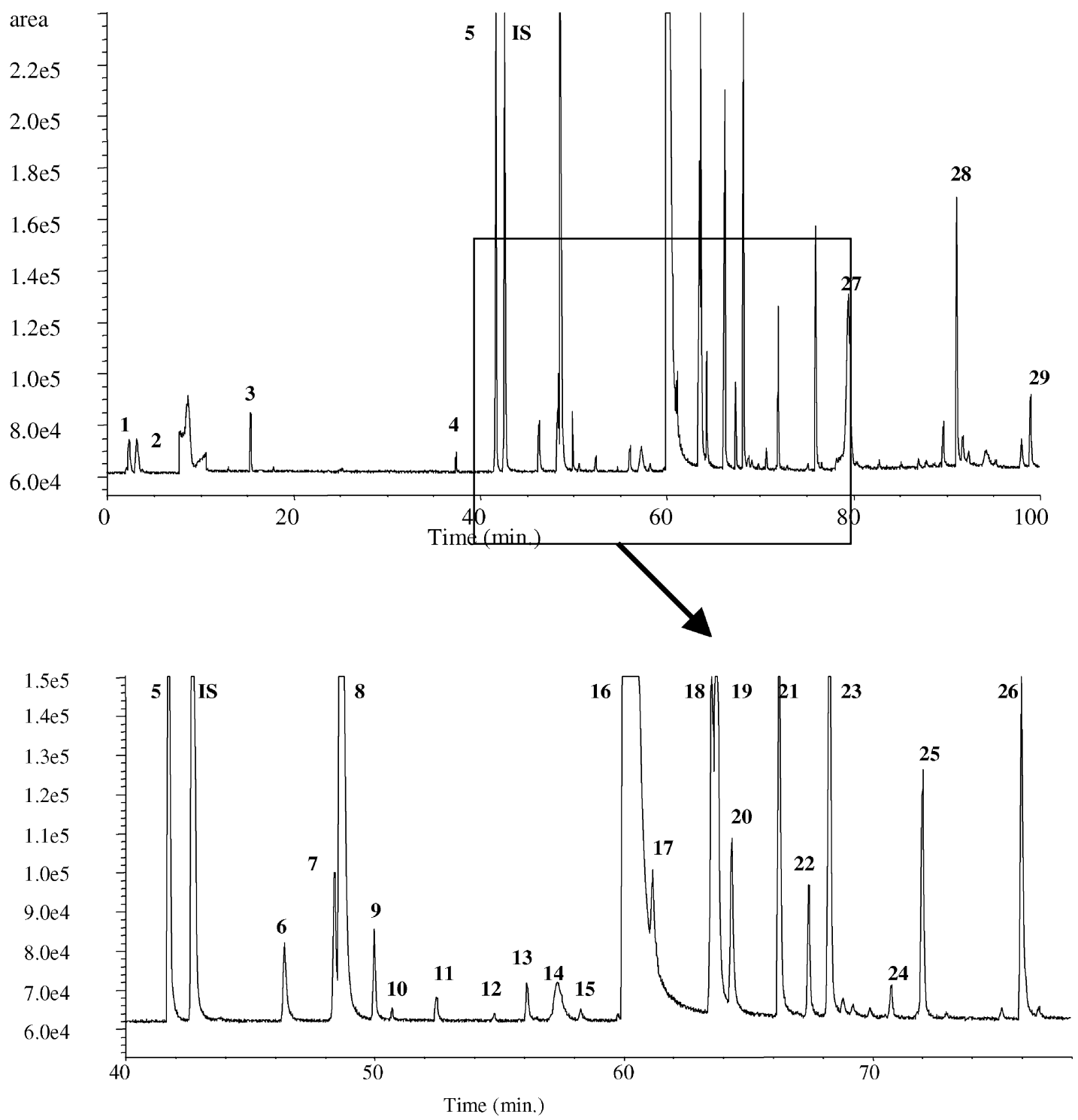

Fig. 1. Chromatogram of sulphur compounds in wine: (1) hydrogen sulphide, (2) dimethyl sulphide, (3) $S$-(ethylthio)acetate, (4) peak $1^{\mathrm{A}}$, (5) peak $2^{\mathrm{A}}$, (6) 2-mercaptoethanol, (7) 2-(methylthio)ethanol, (8) 2-methyltetrahydrothiophen-3-one, (9) peak $3^{\mathrm{A}}$, (10) ethyl-3-(methylthio)propionate, (11) peak $4^{\mathrm{A}}$, (12) acetic acid-3-(methylthio)propyl ester, (13) 3-mercapto-1-propanol, (14) peak $5^{\mathrm{A}}$, (15) peak $6^{\mathrm{A}}$, (16) 3-(methylthio)-1-propanol, (17) peak 7 $\mathrm{A}$, (18) cis-2-methyltetrahydrothiophene-3-ol, (19) 3-(ethylthio)-1-propanol, (20) peak $8^{\mathrm{A}}$, (21) trans-methyltetrahydrothiophene-3-ol, (22) 4-(methylthio)-1-butanol, (23) peak $9^{\mathrm{A}}$, (24) peak 10 , (25) dimethyl sulphone, (26) peak $11^{\mathrm{A}},(27)$ peak $12^{\mathrm{A}}$, (28) 3-methylthiopropionic acid, (29) $\mathrm{N}$-3-(methylthiopropyl)acetamide. ${ }^{\mathrm{A}}$ Unknown substance, IS-internal standard, ethyl (methylthio)acetate. 
detector temperatures were $250^{\circ} \mathrm{C}$. The carrier gas used was $\mathrm{H}_{2}$ at $1-2 \mathrm{ml} \mathrm{min}^{-1}$.

The sulphur compounds were identified by their retention time in a solution of a pure compound and by comparing mass spectra (SCAN mode) and retention times with those of standard references. When no standard reference was available, identification was carried out by comparing the mass spectra with those given in the literature [14] or in the NIST98 database library. For each compound, the non-linear response of the detector was obtained using several standard solutions with different concentrations. The concentrations in wines of commercially available sulphur compounds were expressed as $\mu \mathrm{gl}^{-1}$. For unknown compounds, for those whose reference standards were not available and for 'light' sulphur compounds, the amounts were expressed as the ratio of peak area/peak area of internal standard. The reproducibility of the method was assessed from several analyses of the same white wine. A chromatogram of sulphur compounds in a wine sample is presented in Fig. 1.

\subsection{Statistical method}

An analysis of variance (ANOVA), using the Excel $^{\mathrm{TM}}$ software from Windows $95 \mathrm{~V}$. 7.0, was applied to the experimental data; the results were considered significant if the associated $P$-value was $<0.05$.

\section{Results and discussion}

The variation of hydrogen sulphide concentration in the control wines (no amino acid supplementation) and in wines produced with the addition of cysteine and/or methionine to grape musts is presented in Fig. 2. The addition of $40 \mathrm{mg}^{-1}$ cysteine to grape musts resulted in an increase of the hydrogen sulphide content in all wines. This increase can be explained by an overproduction from cysteine, by the action of cysteine desulphydrase, or by the repression of cysteine synthesis from sulphide through the transsulphuration pathway $[1,5,11]$.

In wines from Alvarinho and Trajadura varieties, the addition of cysteine to grape musts also led to an increase in dimethyl sulphide production (Fig. 3). In general, this increase was also observed for all wines elaborated with the addition of both sulphur amino acids. The data obtained does not support the mechanism of dimethyl sulphide synthesis from cysteine usually proposed [1,3,11]. Another mechanism for dimethyl sulphide formation is the metabolisation of dimethyl sulphoxide $[3,11]$; however, this compound

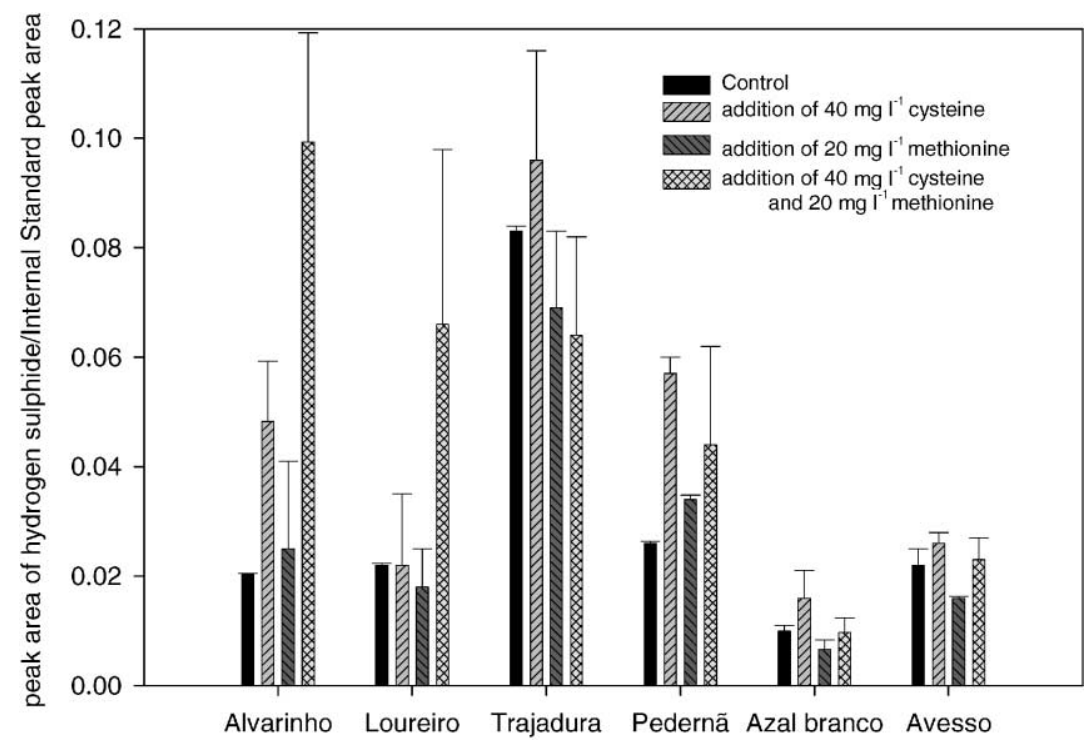

Fig. 2. Hydrogen sulphide content of wines produced from musts supplemented with cysteine and/or methionine. 


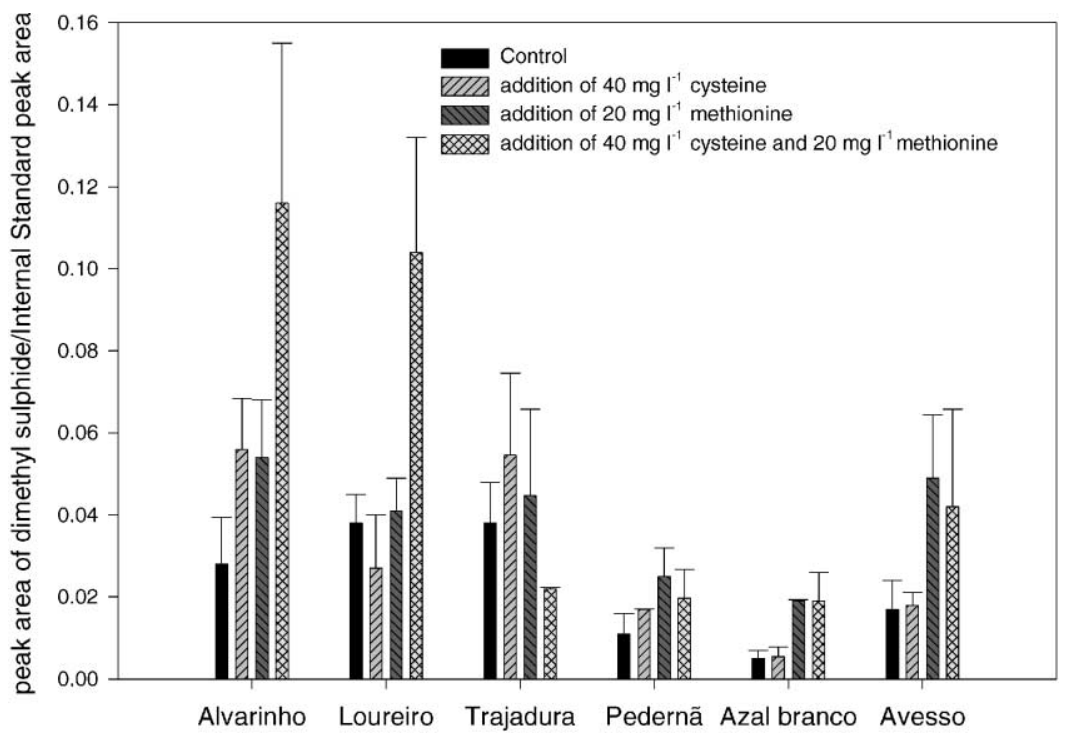

Fig. 3. Dimethyl sulphide content of wines produced from musts supplemented with cysteine and/or methionine.

was detected neither in wines nor in grape musts from Vinho Verde cultivars. The biosynthesis of dimethyl sulphide in wine has not been sufficiently elucidated and further research is needed.

The addition of cysteine to grape musts allowed the production of wines with some differences in less volatile sulphur compounds content, but these differences were not the same for all cultivars. It was proposed by Rapp et al. [12] that 2-mercaptoethanol could be produced from cysteine; however, in the experiments performed, increase in cysteine content of the media led to the production of a higher level of this compound only in Azal branco wines (Fig. 4).

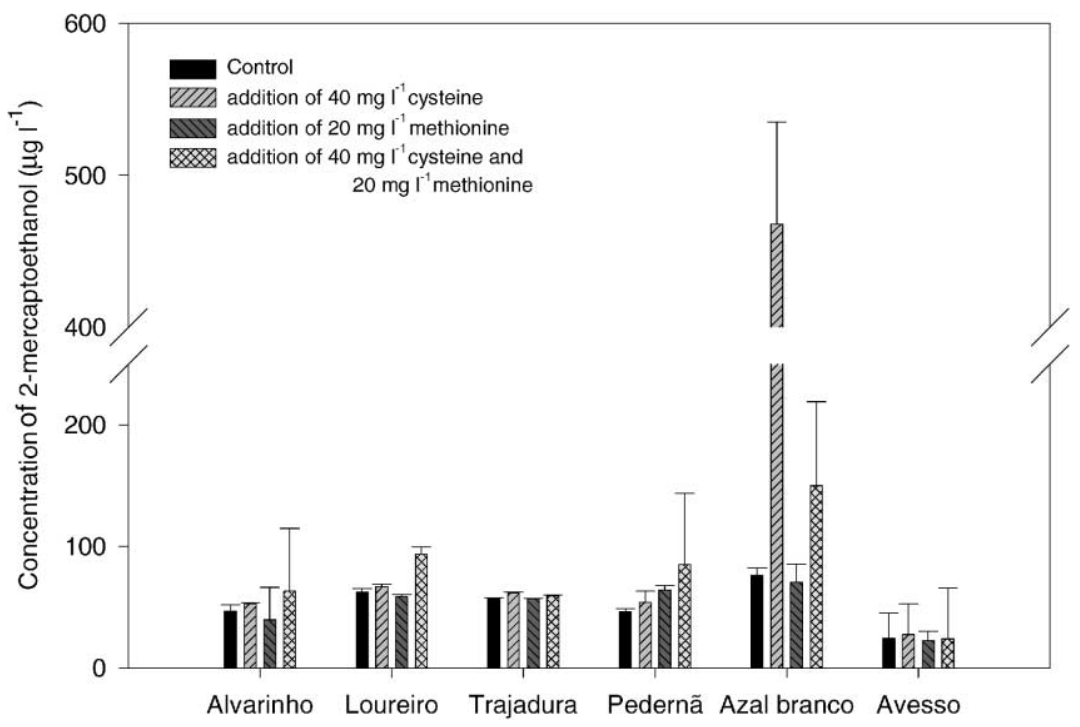

Fig. 4. 2-Mercaptoethanol content of wines produced from musts supplemented with cysteine and/or methionine. 


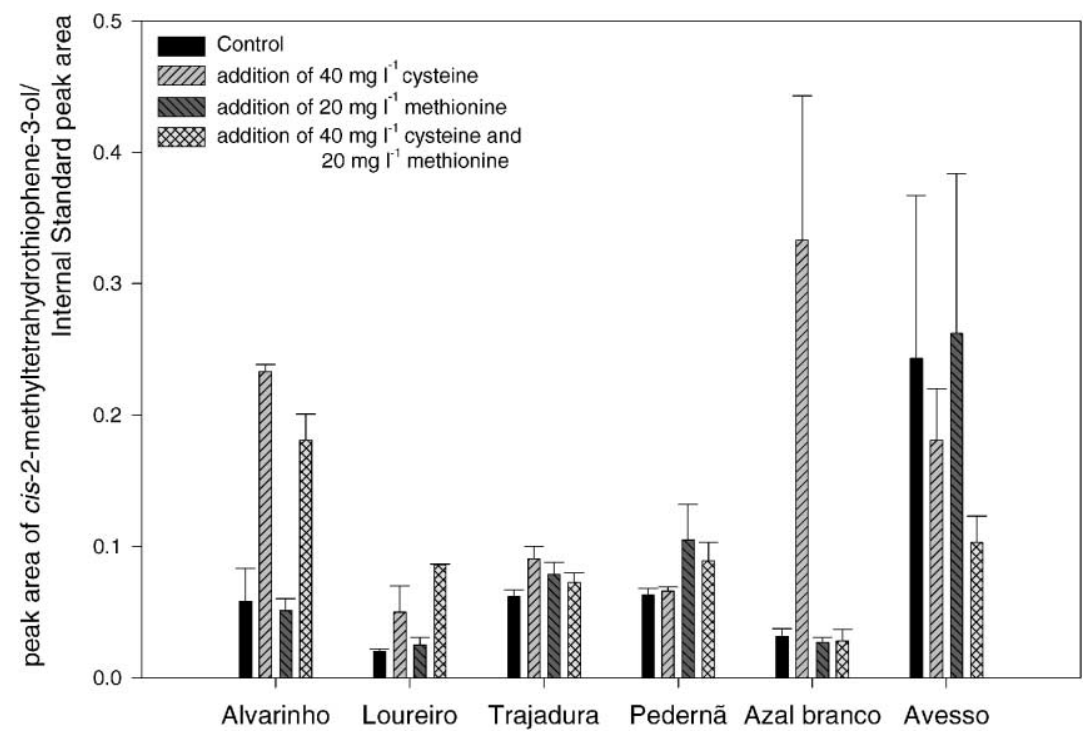

Fig. 5. cis-2-Methyltetrahydrothiophene-3-ol content of wines produced from musts supplemented with cysteine and/or methionine.

The content of cis-2-methyltetrahydro-thiophene3-ol of wines increased with cysteine concentration for Alvarinho, Loureiro and Azal branco cultivars and, to a lesser extent, for the Trajadura cultivar (Fig. 5).

Some unknown sulphur compounds concentrations also increased in wines due to the addition of cysteine to grape musts. This is the case for peak 7 , whose content is presented in Fig. 6, although variations were not significant for Trajadura and Pedernã wines, which have a low concentration of this compound. The cysteine content of grape musts from Alvarinho, Loureiro, Azal branco and Avesso cultivars led to a higher production of peak 4 by yeast (Fig. 7). In Pedernã wines, this sulphur compound was never detected. Peak 2 is

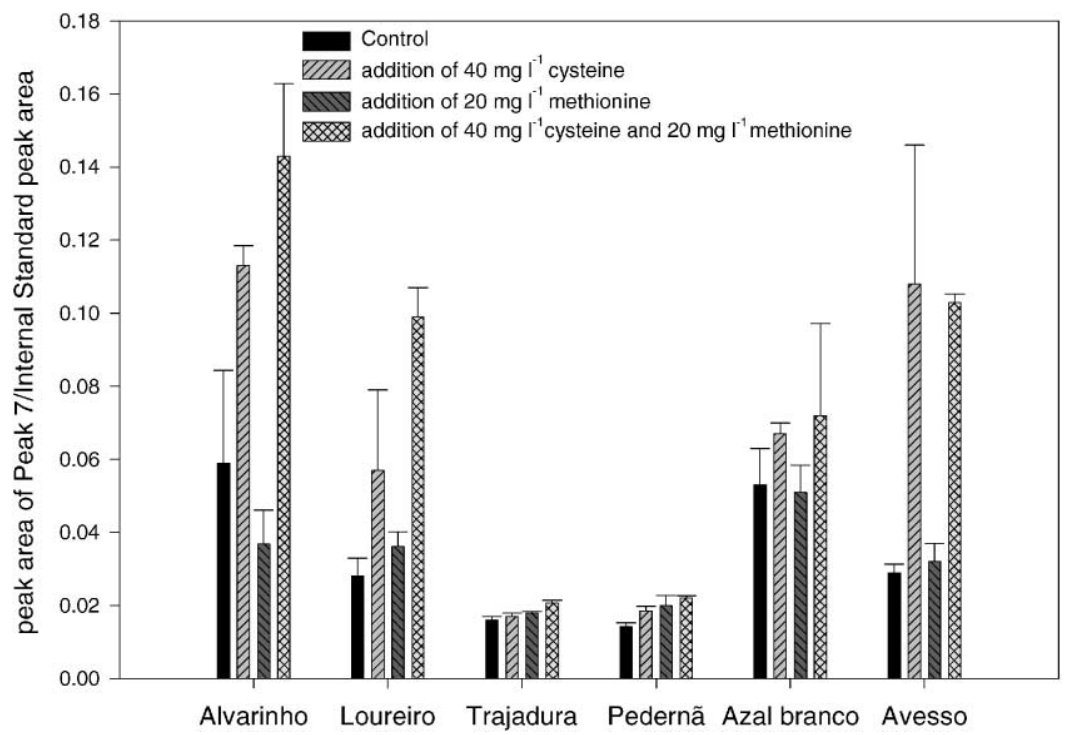

Fig. 6. Unidentified peak 7 content of wines produced from musts supplemented with cysteine and/or methionine. 


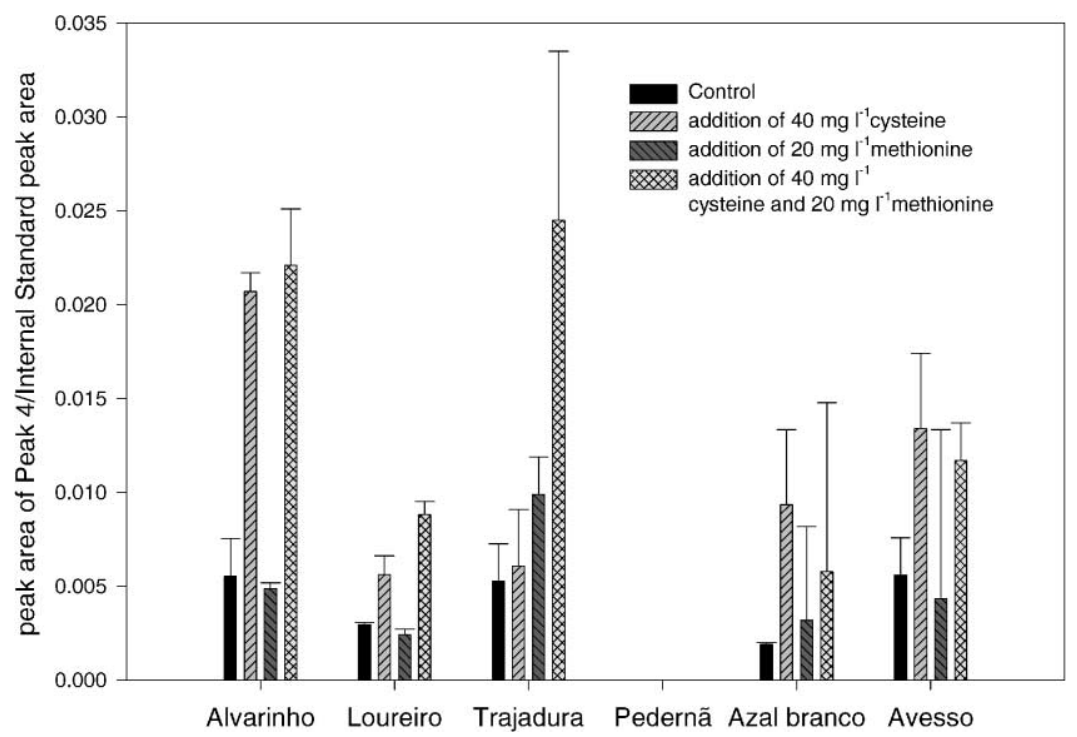

Fig. 7. Unidentified peak 4 content of wines produced from musts supplemented with cysteine and/or methionine.

another unknown sulphur compound whose content in wines increased with the addition of cysteine to grape musts of Loureiro, Trajadura and Avesso (Fig. 8). A decrease of the concentration of this compound with the addition of methionine to musts was observed in every wine.
The addition of $20 \mathrm{mgl}^{-1}$ methionine to grape musts has no great effect on the production of hydrogen sulphide (Fig. 2) which may be due to the repression of sulphide reductase pathway by methionine [2,5,11]. It is also noticed that an increase in the methionine content of the media leads to higher

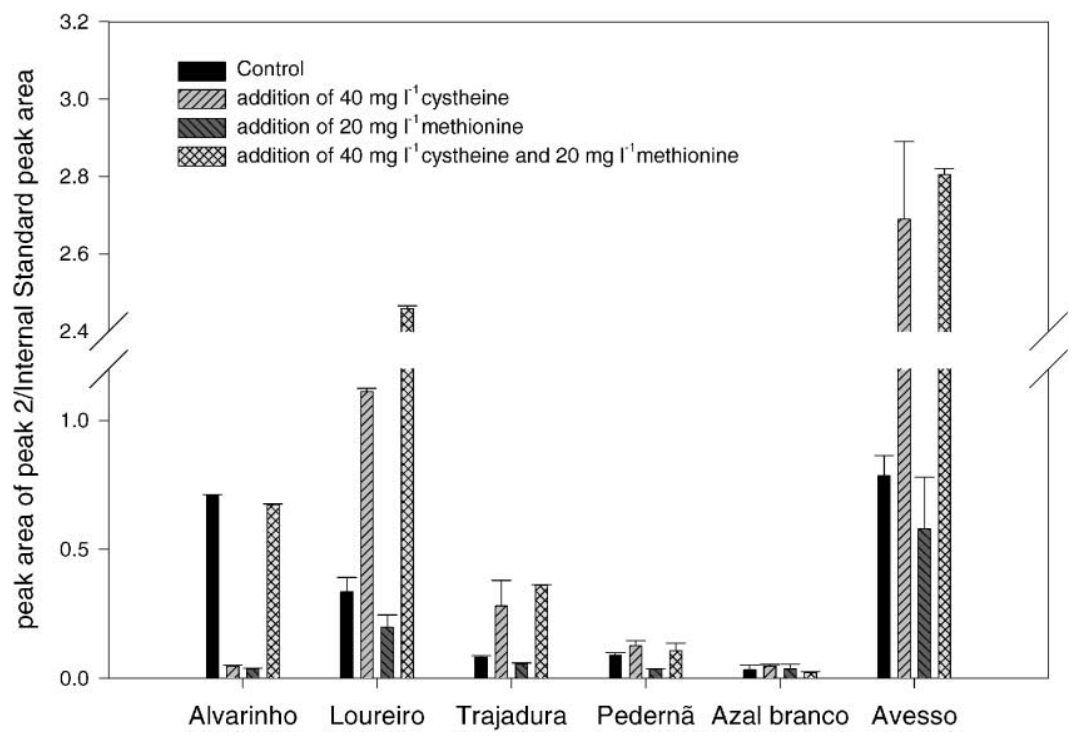

Fig. 8. Unidentified peak 2 content of wines produced from musts supplemented with cysteine and/or methionine. 


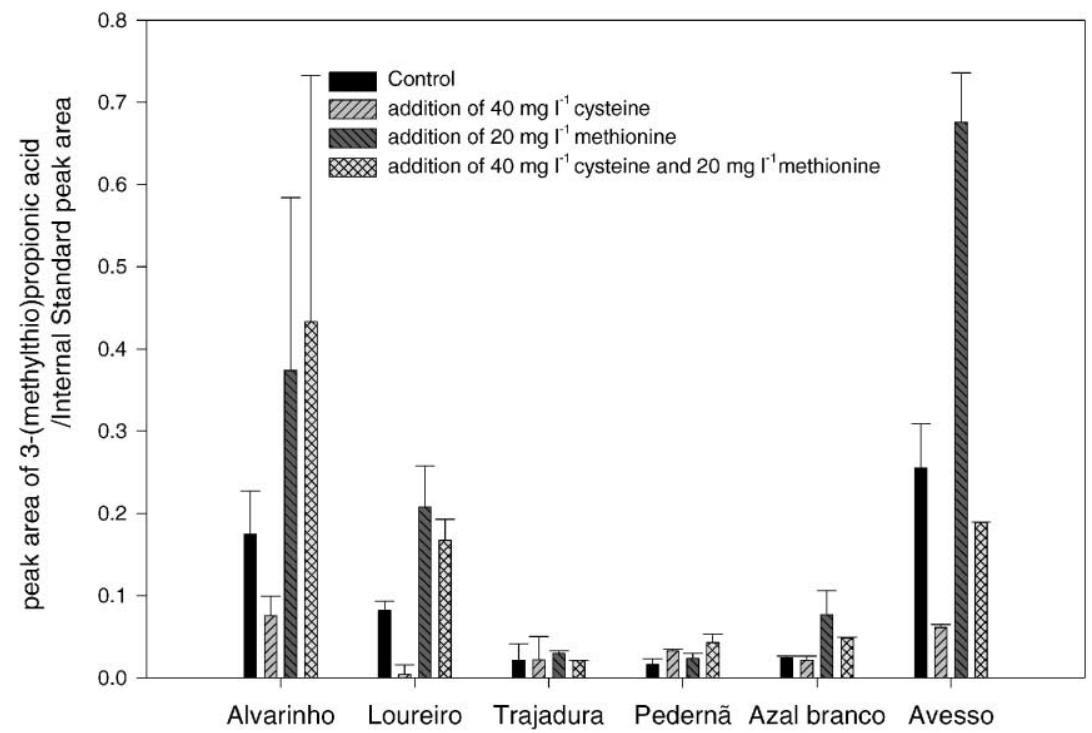

Fig. 9. 3-Methylthiopropionic acid content of wines produced from musts supplemented with cysteine and/or methionine.

concentrations of dimethyl sulphide, mainly in Alvarinho, Pedernã, Azal branco and Avesso wines.

As expected, the addition of methionine or both sulphur amino acids to grape musts increased the content of 3-(methylthio)-1-propanol of all wines (data not shown). In consequence, the production of 3-(methylthio)propionic acid and acetic acid-3-(methylthio) propyl ester also increased with methionine supplementation (Figs. 9 and 10). Similar results were obtained with the addition of $20 \mathrm{mgl}^{-1}$ methionine to Tempranillo cultivars musts [11] and to commercial media [15]. In contrast, the content of 3-(methylthio)propionic acid decreased with the addition of cysteine to Alvarinho, Loureiro and Avesso musts.

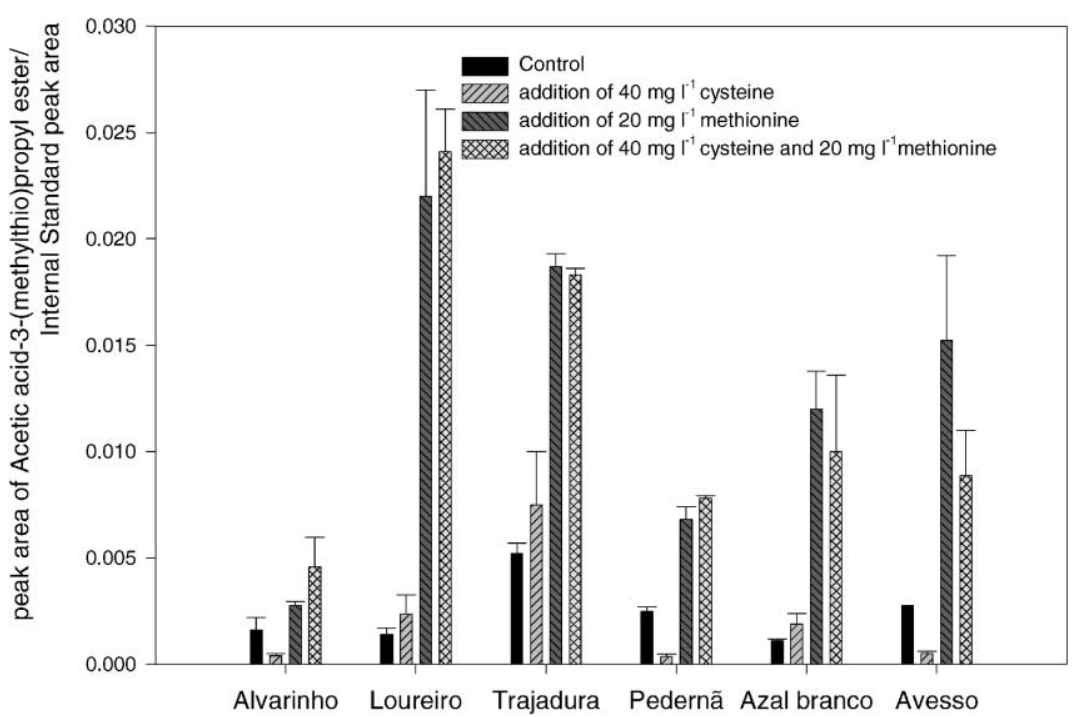

Fig. 10. Acetic acid 3-(methylthio)propyl ester content of wines produced from musts supplemented with cysteine and/or methionine. 


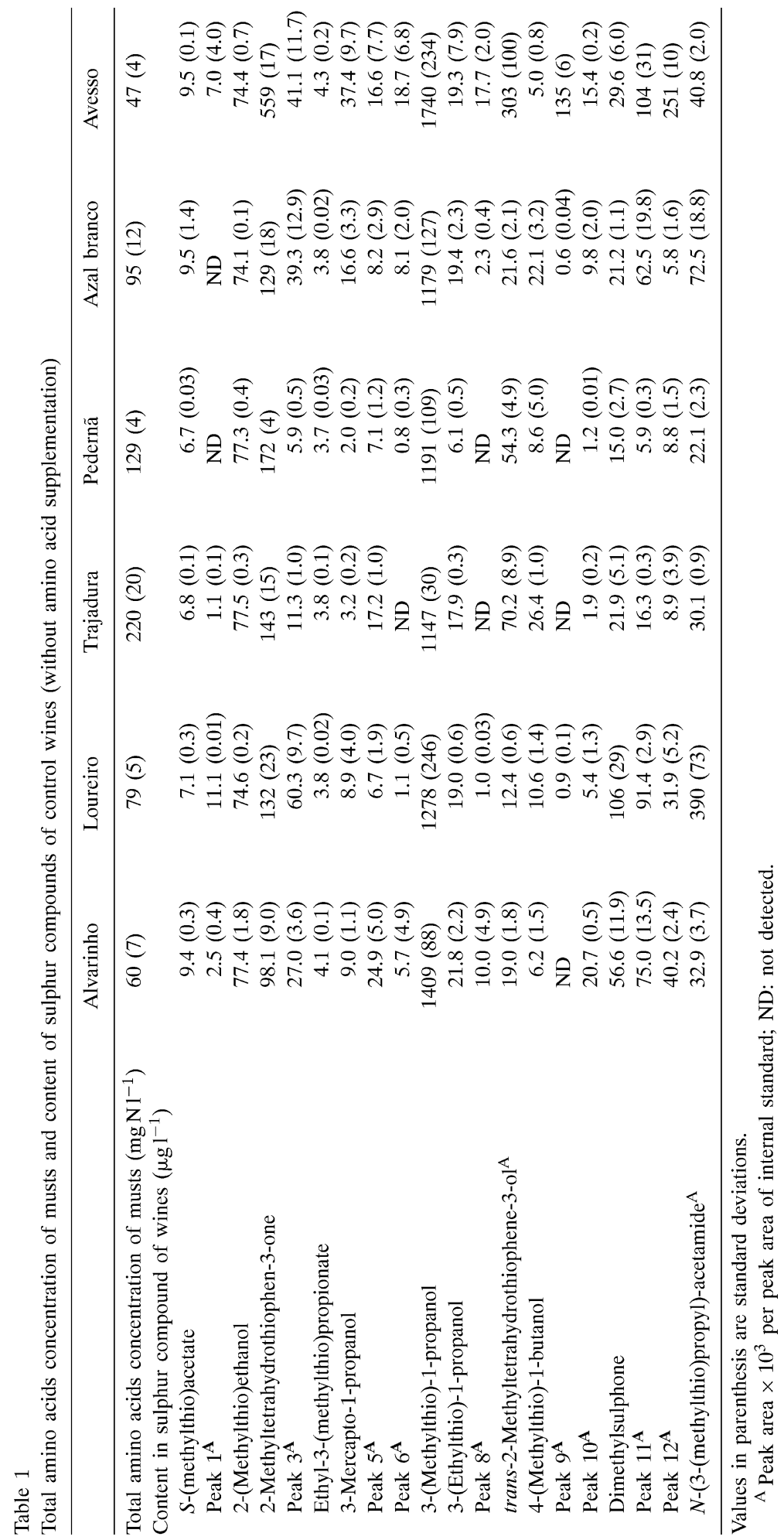


Supplementation of grape musts with both sulphur amino acids led, in some cases, to different effects than those obtained by addition of cysteine or methionine alone.

These experiments showed that the cultivars tested presented differences in the content of sulphur compounds; from the ANOVA, the varieties were significantly different $(P<0.005)$. The total amino acid content of grape musts and the content of additional sulphur compounds in control wines are presented in Table 1. The greatest differences (>5fold variation) in sulphur compounds contents of wines were obtained for hydrogen sulphide (Fig. 2), 3-(methylthio)propionic acid (Fig. 9), 3-mercapto-1propanol, cis- (Fig. 5) and trans-2-methyltetrahydrothiophene-3-ol, $N$-3-(methylthiopropyl)acetamide and the unknown peaks 1, 2 (Fig. 8), 3, 6, 8, 9, 10, 11 and 12 .

Trajadura and Pedernã wines were produced from musts with high total amino acids content, 220 and $129 \mathrm{mg} \mathrm{N}^{-1}$, respectively. These wines have a low concentration of many sulphur compounds such as 3-(methylthio)propionic acid, 3-mercapto-1-propanol, dimethylsulphone, $\mathrm{N}$-3-(methylthiopropyl)acetamide and the unknown sulphur compounds of peaks 1, 3, 6, 7 (Fig. 6), 8, 9, 10, 11 and 12. Nevertheless, the Trajadura wines showed the highest content of hydrogen sulphide, acetic acid-3-(methylthio)propyl ester (Fig. 10) and 4-(methylthio)-1-butanol. The presence of a large concentration of hydrogen sulphide in Trajadura wines is unexpected, because it is well-known that wines from musts with a high nitrogen level normally have low concentrations of this compound [8]. The formation of hydrogen sulphide in Trajadura wines should be further investigated.

In contrast, Avesso wines, produced from grape musts with poor amino acid levels $\left(47 \mathrm{mg} \mathrm{N}^{-1}\right)$, had a high total sulphur compounds concentration, namely 3-(methylthio)propionic acid, 2-methyltetrahydrothiophen-3-one, 3-mercapto-1-propanol, 3-(methylthio)1-propanol, cis- and trans-2-methyltetrahydrothiophene-3-ol and unknown compounds peaks 2, 6, $8,9,11$ and 12 .

Wines from Azal branco are characterised by a high concentration of 4-(methylthio)-1-butanol and peak 7. A high concentration of 3-(methylthio)propionic acid and peaks 2, 5 and 7 is present in Alvarinho wines. A high content of dimethylsulphone,
$N$-3-(methylthiopropyl)acetamide, peak 1 and 3 characterise the Loureiro wines.

\section{Conclusions}

The content in sulphur compounds of wine is associated with the yeast metabolism of nitrogen compounds in the media, but further work is needed to better understand the origin of such compounds. This work showed that wines produced from grape musts of low amino acid concentration present a high total sulphur compounds content. Addition of methionine to grape musts led to a higher production of 3-(methylthio)-1-propanol and, consequently, of 3-(methylthio)propionic acid and acetic acid-3(methylthio)propyl ester. Higher contents of hydrogen sulphide and cis-2-methyltetrahydrothiophene-3-ol were obtained in wines produced from musts supplemented with cysteine. An increase in 2-mercaptoethanol concentration was observed only in wines elaborated from Azal branco cultivar supplemented with cysteine.

Some unknown sulphur compounds detected in wines are shown to be related to the sulphur amino acids content of grape musts. Further investigation is needed in order to identify these compounds and their biosynthesis mechanisms.

This work showed that cultivars from the Vinho Verde Region in Portugal have different sulphur compounds contents. Research work on the sensory characterisation of wines continues in order to find sulphur compounds related to organoleptic quality.

\section{Acknowledgements}

The authors gratefully acknowledge the financial support from FCT and PAMAF (INIA, Project 2025).

\section{References}

[1] P. Ribérau-Gayon, Y. Glories, A. Manjean, D. Dubourdieu, The chemistry of wine stabilization and treatments, in: Handbook of Enology, Vol. 2, Wiley, Chichester, 1999.

[2] A.A. Beloqui, A. Bertrand, Ital. J. Food Sci. 93 (1995) 279.

[3] V. Lavigne, Recherches sur les composés soufrés volatils formés par la levure au cours de la vinification et de l'élevage 
des vins blancs sec, Ph.D. thesis, University of Bordeaux II, Bordeaux, France, 1996.

[4] S.J. De Mora, R. Eschenbruch, S.J. Knowless, D.J. Spedding, Food Microbiol. 3 (1986) 27.

[5] D. Rauhut, in: G. Fleet (Ed.), Wine Microbiology and Biotechnology, Harwood Academic Publishers, Chur, Switzerland, 1993, p. 183.

[6] M. Stratford, A. Rose, J. Gen. Microbiol. 131 (1985) 1417.

[7] P.A. Henschke, V. Jiranek, in: Proceedings of the International Symposium on Nitrogen in Grapes and Wine, The American Society of Enology and Viticulture, Seattle, WA, USA, 1991, p. 172.

[8] P. Guidici, R.E. Kunkee, Am. J. Enol. Vitic. 45 (1994) 107.
[9] P.J.A. Vos, R.S. Gray, Am. J. Enol. Vitic. 30 (1979) 187.

[10] C.W. Bamforth, B.J. Annes, J. Inst. Brew. 87 (1981) 244.

[11] A. Anocibar Beloqui, Contribution a l'étude des composés soufrés volatiles des vins rouges, Ph.D. thesis, University of Bordeaux II, Bordeaux, France, 1998.

[12] A. Rapp, M. Güntert, J. Almy, Am. J. Enol. Vitic. 36 (1985) 219.

[13] L. Pripis-Nicolau, G. Revel, S. Marchand, A. Anocibar Beloqui, A. Bertrand, J. Sci. Food Agric. 81 (2001) 731.

[14] A. Anocibar Beloqui, P. Guedes de Pinho, A. Bertrand, Am. J. Enol. Vitic. 46 (1995) 84.

[15] N. Moreira, F. Mendes, P. Guedes de Pinho, I. Vasconcelos, in: Proceedings of the Enologie 99, 6th Symposium International d'Enologie Tec. \& Doc., Paris, 1999, p. 314. 